\title{
Political Development and the Influential and Distributive Crises
}

\author{
Akbar Ghafoori ${ }^{1} \&$ Esmail Ahmadi Kafrudi ${ }^{2}$ \\ ${ }^{1}$ Department of Political Science, Yazd University, Iran \\ ${ }^{2}$ Yazd University, Iran \\ Correspondence: Akbar Ghafoori, Department of Political Science, Yazd University, Iran.
}

Received: May 15, 2016 Accepted: June 2, 2016 Online Published: June 29, 2016

doi:10.5539/jpl.v9n5p220 URL: http://dx.doi.org/10.5539/jpl.v9n5p220

\begin{abstract}
Political development theorists believe that political societies, in their development stages, subject to a series of quintuple crises (identity, legitimacy, participation, and influence, distributive). These crises are either in terms of increasing level of development in some communities toward the environment, or to the contrary, in terms of backward countries' failure to cope with environmental changes. Countries, especially third world countries in transitions to political development, undergo crises, including the crisis of penetration and distributive, which in the absence of empowerment in overcoming these crises; the communities will have problems and anomalies. This article aims to analyze the penetration and distributive and to examine the role of these crises in the political development process.
\end{abstract}

Keywords: penetration crisis, the crisis of distributive, political development

\section{Introduction}

In general, with any view to the concept of development, therein lies a kind of transition, a transition from the existing situation to the desired situation. Political communities are always subject to a series of political crises; these crises are in terms of increasing level of development by some communities in the environment, or in terms of the backward countries' failure from coping with environmental changes. Understanding the crisis is including the problems and issues that its dimensions and angles examination has begun scientifically in the 1960s. Lucian Pye, binder, and.... those are who have dealt with kinds of crises with the modern Government. A crisis with the Government have a great importance, because potentially, they could threaten the governments and regime's stability and existence, and from this perspective, harness and "crisis management" is of great importance to political decision makers. "Binder and others" in the book "crisis and succession in the political development", know the condition to achieve political development, through the five crises, which include: 1) an identity crisis 2) The crisis of legitimacy 3) penetration crisis 4) Participation Crisis 5) distributive crisis. Distributive and penetration crisis, compared to other crises in theory are less studied. These crises, in the lack of knowledge or proper management, can face the society with many problems. In this paper, it has been tried examining the crisis of distributive and penetration that has been less considered, theoretically and scientifically.

\section{The Definition of the Crisis and Its Features}

Mahdi Norouzi Khiabani wrote in the dictionary of political terms that the crisis is known as synonymous with a watershed event and turning point. (Norouzi Khiabani, 2002: 56). In the dictionary of international relations translation of Hossein Posta, the word of crisis has been studied from an economic standpoint and defined the crisis as "Business and trade situation in the Great Depression of economic" (Plano, 1996: 175).

From Almond and colleagues, point of view, the origin of the crisis lies either in the nature of any political system or in environmental factors. A crisis that comes from the nature of the system; the theorists call it crisis derived from the system. Based on an analysis of the political system, Almond and colleagues argue that any system in addition to the trend toward stability, deals with crisis and instability as well (Seyfzadeh, 1994: 121).

From their perspective, the crisis begins with previous stage of symmetry first. This asymmetry either is due to either the nature of the system, or caused by environmental factors in an internal or external scene. The crisis that caused from environmental factors is usually due to changes that caused by the international scene. However, the origin of the crisis, either environmental factors or factors derived from the system creates an asymmetry in the system that an action is needed to fix it. The action is to resolve the crisis of the third step that in the fact it is called 
step through the barrier. This step includes disorders of officials to fix it. At this point, the various alliances and policies form in order to create symmetry again that is the fourth step of the above sequence. The fourth step involves structural changes in the environment and distributive that takes place if the occasion arises (Seyfzadeh, 1994, 122-121).

Saif Zadeh quoted Flanagan, has defined the crisis. Crisis is a situation in which the use of illegal means to protest that used by the protesters, the legal authority of decision-makers will be in jeopardy. This risk is to the extent that the authorities' power highly threatened in protecting the regime or staying in power. In other words, the crisis is a situation where non-compliance is provided to the rules at least field (Seyfzadeh, 1994: 120).

Tajik quoted Rainer and Kan in a comprehensive manner has provided following definitions for the crisis.

1) A turning point in the events and actions that brings unexpected consequences

2) The situations that demand the urgent action of participants

3) A serious threat to security

4) The conditions that create high uncertainty

5) Loss of control over events

6) The conditions in which the information available will severely reduce

7) Creating new conditions arising from the interaction of several events (Tajik, 2000: 34)

In the event of a crisis, in various fields of political science, expressions of distress, horror, tragedy, disaster, potential and actual violence in the political system will outbreak. In various fields of political science, the sense of crisis was considered with various meanings, such as distress, horror, tragedy, disaster, potential and actual violence or as a turning point in the analysis of decision (Seyfzadeh, 2009: 117).

"James Robinson" believes that, terms such as "pressure" Tension, disaster, anxiety, panic, are also included words that are related to the crisis. From his point of view, "pressure", means the neutralization or neutralization probability of a selective mode leads to sensational action. The negative effect is the result of constant pressure. Pressure means a threat to the goals, the only one main element of the crisis. Conflict is also an incompatibility between various parties towards the goal (Robinson, 1999: 124-123).

The emergency is a situation whereby the life and order of a government will be at stake, so that, it cannot return to normal through natural processes of the constitution.

\subsection{The Origin of the Crisis}

Binder believes that the crisis is created because of contradictions between triple symptoms of development means "cultural equality", "economic capacity" and "social segregation". (Seyfzadeh, 1994: 174). Talcott Parsons, with functionalist theory, believes that the disorder in each of the quartet functions of a society, meaning 1.The implementation application with new conditions2. The resolving social tensions application 3.Achieving the goal application 4.maintaining social cohesion application, are sort of crisis. In Parsons' theory, the system is discussed as a biological organism or living system. From Parsons' perspective, solidarity and continuity factors of the system include:
1) Values
2) Norms
3) Institutions
4) Roles

Social system of action has demands that must be satisfied, so that the system remains stable. In addition, it has components that act to meet these needs. All systems have a tendency to balance with a sustainable and balanced relation between the various components and protecting itself from the other systems. "Lucian Pye" believes that political development is increasing the capacity of the system in order to respond the needs and demands of the people, structural diversity, specialization of structures and raising political participation.

"Raymond Aron," the French sociologist says, "we know less generation that has not felt that it is in the crisis, or in other words, in the turning point of history" (Kazemi, 23: 1995).

The so-called crisis is the translation of the "Crisis» that is a Greek word and brings an unusual situation, horrifying, emergency and violent in mind. When the crisis will happen that value, interests and important goals they will be threatened. About the reason for happening crisis, «Binder» and «Pye» have divided this issue into 
five crises framework that include identity crisis, legitimacy crisis, participation crisis, penetration crisis, and distributive crisis. (Ayvazi, 196: 2003).

1) Disruption in philosophies and values of society

2) Disruption in the traditional and the legal system

3) Disruption in behavioral and individual system

4) Disruption in organizational and structural system

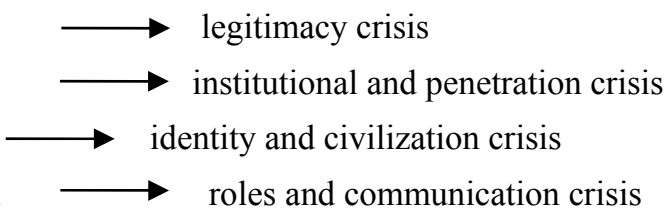

5) Disruption in the development, expansion and modernization system $\longrightarrow$ Distributive crisis

In the most general case, all crises will challenge the ability of the ruling elite. Such challenges in each of the critical areas exert the necessary pressure for reducing old institutions or creating new institutions to the elites.

\section{Penetration Crisis}

\subsection{Penetration and Penetration Crisis Definition}

In the most general case, a "penetration" is announced in the sense of identification with public policy by the central government's authority. The penetration of any government equals to run policies of the government probability that is related to the whole system of government or any of the subsections, at least as far as these policies or rules that can be extracted from it, are relevant.

Penetration phenomenon has two interconnected aspects: the first dimension can be imagined as the central government's ability to achieve penetration, regardless of the views, aspirations and attitudes of those who are policy issues. The second penetration aspect deals with the existing or modified ability and readiness in order to accept or reject the politics from those who are policy-making topic and audience. Varying degrees of such ability and readiness has inextricably and obvious connection with what has legitimacy (Lapamombara, 2001: 319).

In terms of analysis, what makes the penetration crisis distinguish from other crises is that the crisis could be with incoming pressures on elites, to make institutional adjustments or innovations in specific spectral. Penetration crisis, like distributive crisis primarily linked with major changes in the functioning of the government and some of the consequences of the political system. Although, these changes deal with the psychological aspects and mainly with crises that have psychological roots directly, but our attention is on specific institutional arrangements and their reforms (or lack of terms) over time.

Political elites different perspectives, penetration refer to the fact that if they can get what they want from the people under their own power. Such power clearly refers to the part of government policy that is largely beyond taxation and conscription. It also includes a complete area of measures related to social welfare, modernization, new styles of political participation. The obtaining compliance with such policies issue, not only refers to geographical subdivisions of the state, but also social, ethnic, linguistic, racial, social and other subdivisions (Lapamombara, 2001: 320-319).

We can say that this crisis refers to the ability of government's penetration in depth of the society. This crisis underlies to determine the matter that to what extends the society knows the government decisions benefit from it and to what extent it is committed to implementing it. According to what was said, the penetration crisis stems from the requirement that existing governance structures should adopt a policy that would encompass the entire population and is consistent with the daily life of people. Resolving these new issues is possible through the series' creation of local, regional, and national institutions that act their competence even in the most remote villages. This matter is also requires continuous song intervention definition (programs, nationalization, government regulation, economic, social, cultural policy making ...).This means to create motivations that create trust between leaders, overcome the indifference of the subjects, and provoke the real expectations in the field of governmental policies among them (Badi: 2008: 71 -70).

To overcome this crisis, the areas of government's decision-making power increasing and its dominance over the entire territory of the country should be provided. In this process, the political system must be able to create the necessary fields to build trust between the people and officials. In a sense, the penetration crisis is under the influence of other crises. For example, in circumstances where the state faces with legitimacy crisis, the exacerbating of penetration crisis will be provided. In addition, the penetration crisis increasing, in the long term, will create the legitimacy crisis (Ghavam, 187: 1995).

The main indicator of the crisis and universality in the lack of trust development, and acceptance of people's process, especially those who have harmed from the development process to the government and leadership. In the 
situations that the penetration crisis will be the indicator of the relationship between rulers and ruled, often socially excluded groups commit violent riots and protests. Urban violence may be in the form of organized, like labor strikes, anti-government protests, assassinations and sabotage.

In this case, sub-national groups, including ethnic, religious, linguistic or racial that observe a loose national allegiances and relations with the central government, they choose a diverge process that may lead to the dissolution of the national and separatism (Kazemi, $1997: 59$ ).

\subsection{The Penetration Crisis Incidence}

On the prospects of development theory, Argansky's analysis that links "the crisis attitude and the stage attitude" to each other, has a prominent position. This analysis is based on the assumption that all societies will reach development by passing through four successive stages: the initial stage of unification, industrialization stage, the favorable situation stage and the abundance stage.

Argansky believes that in any of these steps, the existing political structures faced with particular issues and particular crises, that the transition from this crisis requires a special specific task. Hence, the development is subjected to do the special work based on good coordination with the community's situation and its historical stage. From Argansky's point of view, the transition from the initial unity phase is usually simultaneous with the penetration crisis experience by political systems. At this stage the power will be distributed and often divided between the center and the periphery in the asymmetrical and unevenly way;

The central government does not have enough power to influence its land, the central government has less ability to mobilize the population and the governments and the national, local groups are as the government's competitor. In such circumstances, the government's method is directed towards the development and strengthening of center political and administrative monitoring of the population. These orientations are for significant strengthening of the political elites' role through the development of administrative, civil and military, and trying to draw up comprehensive legislation.

Due to these functions, the government drags to authoritarian behavior and the threat of political participation and regulate conduct within a political culture more subjugation than participatory. These policies make the governments face with penetration crisis and pervades during the development process (Badie, 77: 2008-75).

In countries with variety of ethnic, racial, linguistic, religious, usually the governments, in the transition of the development process, face with a huge range of demands and requests on behalf of the national groups, that due to weak political and administrative structure, such governments are often not able to supply and meet imported demand to the political system and this leads to non-compliance of sub national groups from the central government and national allegiances break and the government faces with the penetration crisis.

Other factors of penetration emergence crisis and cognition in societies in transition are poverty and institutional vacuum that almost can be seen in all functional areas involved in the renovation dramatically. In such communities, needed institutions either do not exist or do not able to play and perform their function.

At the same time, planning and communication that are deemed as key areas, are suffering from serious deficiencies. Decision-making and planning techniques usually are imitative and inappropriate and on the other hand, they bring a lot of communication, demands and expectations which there are not appropriate infrastructures in order to meet them (Dayoob, 1998: 51-50).

\subsection{Solving the Penetration Crisis}

Since the penetration crisis deals with both the corporate and social-psychological dimensions, it leads our attention to the structural aspects of the organizations, and how they can be established in the most rational and efficient way.

Joseph Lapalombara states, three basic issues that affect the penetration crisis management:

1) generalizing to deal with the penetration crisis by using special patterns for organizing with others is would not simply be possible. For example, if the realization of some ideal concepts of the modern state requires some sort of Weberian system public bureaucratic organization, certainly in some countries, these patterns realize with more delay than other model patterns.

Full independence bureaucracy of social and political control leads to pursue their personal interests. In other words, it can be called a necessary balance between the free flow of bureaucracy and its affiliates to the political or social groups within the political system, and where the members of the bureaucracy, organizations are merely the hand tool for influence political class, they show unwillingness to resolve the crisis, or on the other hand, the bureaucracy complete independence from the social and political control, leads them to pursue their personal interests.

2) The geographical penetration problem for most developing countries is the most important thing. This 
penetration can be acquired by military organizations, but even when such a thing is possible, it needs more organizational innovation. It can be said that the first requirement is producing team of office managers or educating them, not only in the center, but also in places where these managers do not know the shortsighted sensitivity, and negative public response capabilities as their main concern.

3) Responding to the penetration crisis is entirely based on the "biography" of concerned nations, such a description represents such things as the needs and objectives of public policy and human, physical and organizational resources, which have to mobilize in order to achieve the goal and to remove clear barriers that are within the system and on the basis of these factors, it is estimated what can be done and at what time (Lapalombara, 348: 2001- 346).

Most of penetration problems are related to the diversity of law and order. The government should do something that, its presence will be felt in remote areas, and this need will have arrangements in the form of military, tax collectors, judges, police and administrative authorities.

Resolving the cognitive and penetration crisis is possible through the creation of national, local and regional institutions series, which apply their competency even in the most remote areas. This also requires continuous intervention in the form of national programs, government regulation, and economic, social and cultural policy. Finally, resolving cognitive and penetration crisis means to create a mechanism that brings mutual trust between the government and the people of the community (Badie, 2008: 71).

"Lucian Pye" in the book of political development aspects, offers an efficient manner in order to tackle and solve the crisis. The starting point of the Pye's analysis is in the most classic line of development orientation practices. In fact, Pye states that all communities have only one trilogy method to overcome the crisis, including the penetration crisis that the components of this universal approach include:

\section{1) Equality Strengthening}

2) Upgrading and increasing the capacity and efficiency of government

3) Realizing the structural distinction at all levels of the system (45-47: 1967, pye).

Solving the penetration crisis depends on the issue that, mutual understanding of people and the government will be provided from social issues and processes. In order to overcome the penetration and cognitive crisis, it is necessary to make a comprehensive attempt of the political system in the development process, in order to achieve the new nation-building and state-building capacity, so, nationalism as a force for creating an internal integration of developing countries, can be considered an effective tool in the hands of development oriented government, in order to apply influence on people, regions and different groups of society and as a driving factor for development purposes. (Sariol Ghalam, 1996: 14). The process manifests through creating and institutionalizing two new patterns:

1) New pattern, "assembly and penetrate" that is able to adjust and involve the growing roles of the system.

2) New patterns, "contribution and distributive" of sources to the extent that have the sufficiency to meet the egalitarian demands of the system. (Seyfzadeh; 123: 2009)

So, to overcome the penetrating crisis, reaching the level of "convergence", "mobilization" and the process realization of "nation-building", which "Karl Deutsch" says, such a goal is possible through "social mobility" and development of "communication". The major criterion for political development, in terms of Deutsch, is the social mobility. According to Deutsch, social mobility is a process whereby traditional beliefs and affiliations will change in the fields of political, economic, psychological, social, and cultural and make the people ready to accept new behavioral patterns. (Ghavam; 15: 1371)

Community development, which leads to development realization; firstly, increases the central government's influence over all its territory, secondly, increases the government's ability in identifying requests and demands of different individuals and groups in society, and thirdly, increases the government's ability, to meet the demands and responding the needs and demands of the people.

Deutsche concerns and analyzes the realization of this process in terms of national development term. National Development in the analysis of Deutsch is considered as a set of processes that help the integration between the considering people in the political system depending on one center. In this way, Deutsche induce the hypothesis that this integration (National Development) will be implemented in real time when a certain level of economic development is reached, so that the least relations will be established between different sections of society. The gradual establishment of such a network of communications is exactly the social mobilization production, according to Deutsche, this is the best solution to the penetration and cognitive crisis in which all members of 
society will be absorbed in general social and political circles. In this way, we can overcome the penetration crisis, and through this; we can initiate the new mechanisms of integration and socialization, which are the most important factors in creating a national community.

Therefore, in this theory, Deutsch provides a list of four indicators, which can specify the mobilization of a society and achieve nation-building process, which is included in these items. Economic data (income, the population division in various sectors of activity), Cultural data (literacy, buying newspapers...), demographic data (degree of urbanization) and the political data (voting participation, nomination in an election ...) (Badie, 2008: 38-36).

Different political systems, in terms of dealing with the unexpected transformation, have not the same capacity and capabilities. Potential capacity to deal with new forms of political demands is possible only if the system has passed the stage of political modernization. Political modernization features are as follows:

1) A high degree of diversity in the roles and political institutions

2) Expansion of the central political and administrative organizations' activities and their gradual expansion in all areas and sectors of society

3) The desire to accelerate the potential power to wider groups and finally its dissemination to all citizens

4) Having non-governmental organizations (Ghavam, 93: 1992).

Since the penetration crisis will test the organizational, technological and diplomatic abilities of the ruling elite, one of the ways to solve the problems of the administrative, political system in developing countries and consequently resolving the penetrating crisis is the implementation of decentralization instead of focusing oriented. Hatneh, 2009: 23). Centralization is a way and policy that according to it, the central power means ministries and the supreme administrative authorities that usually are at the center, are responsible for the regional affairs and administrate local affairs by subsidiaries officers.

However, in decentralization: the distributive of administrative and government power through the division of powers and governmental tasks between the central, local, regional and area powers. On this decentralism way, and administrative and government laws and regulations formulated in a manner that, the administration of the country has not centralization and provides the possibility to transfer the power from the center to the organs. (Www .Ebook91.blogfa.com).

In this system, the central power entrusts part of its authorities to competent and qualified local authorities and organizations. The local authority organizations are usually limited in comparison to the authority of the central government and this difference is in all aspects including technical, organizational and political. In the decentralization pattern, each area affair is usually regulated according to local amenities. This accurate and timely arrival process guarantees all the demands of the population in the political and state systems and helps to resolve the penetration crisis.

\section{Distributive Crisis}

\subsection{Distributive}

Distributive importance in the process of modernization and political development is to the extent that some of the political scientists have described the policy as value distributive of authority. In this regard, we must see that how the system power will be applied in the distributive of resources, services and values of the community and what groups and segments of society benefit from system activities.

Easton knows the political system a set of mutual actions that through it, values, goods and services will be distributed among different sectors of society in terms of reliable power. His purpose of authority distributive is the decisions of the legislative, executive and judicial authorities. (Ghavam, 180: 1995)

Given that, there is a wide range of interests, which could lead to political demands, we must admit that a lot of these demands are material, "Maslow" states quintuple list of his famous human needs hierarchy as follows:

1) Physiological needs: food, shelter, sexual satisfaction, and other physical needs.

2) Safety needs security and protection from physical and emotional injuries.

3) Social needs affection, belonging, acceptance and friendship.

4) Value needs (respect): internal value factors such as self-respect, self-determination and progress with external value factors such as position, reputation and attention.

5) Self-actualization needs: to actualize the potential talents, to gain satisfaction, achievement motivation to demands, according to competency and merit (D Kenzo,: 15: 2000). 
It should be noted that, the range of "value affairs" involves all forms of human needs and aspirations in an organized society. The well-known list "Lasswell" of human values will lead us to the truth that human will not live or die for bread. It includes the human need to respect, attention, dignity, compassion, interaction... Requested demands from political elites are very symbolic and more psychological rather than material, such as requested demands in the identity and legitimacy crises (Lapalombara, 362: 2001).

Easton says, "In summary, the distributive of authority divides and distributes the value affairs into one of three ways

1. This distributive may deprive a person of value thing that he had until now.

2. Mentioned distributive prevents accessing values that otherwise the achievement of them exists.

3. This distributive provides access some people's values and prevents accessing of others to it.

\subsection{Distributive Crisis}

In countries where there is the greatest and most efficient type of national sovereignty, elites will be well organized, masses have remarkable loyalty to the country and they have a central government, the ideological gap cannot take seriously the society, the elite can react the best to the distributive crisis.

Distributive Crisis founded after the First World War. This crisis means what roles the governments have in an economic adjustment in order to create social justice. In general, in this crisis and for the first time the attention to social justice issue is raised. Governments are taking the relative prosperity in the community responsibility and monetary policy, financial planning, economic and investment control in order to solve the distributive crisis. It must be said that the distributive crisis is related to the governmental power's way in the distributive of goods, services and values in the society. This crisis stems of the obligation to arbitrate between different social groups, the decision to determine needs in terms of mentioned priorities and the efficient distributive method. Solving this problem, generally is possible through government interventions strengthening and developing the administrative apparatus (Badie, 71, 2008). In describing the distributive crisis, it should be said that the development has not one aspect but it has various aspects. The distributive crisis takes place in three political, economic, social levels. On the political side, the distributive crisis is concerned the concentration of power in one spot and depriving other sectors of society in the decision-making power and playing role. In these circumstances, the majority of societies are indisputable. While a small group is the real decision-makers and policy makers. While political modernization requires the majority of society input to the policy-making process. While most people are barred from interfering in their destiny, we cannot expect the community steps toward political development (Ghavam: 1995: 180).

\subsection{Distributive Crisis Incidence}

In Argansky's analysis that linked the attitude of the crisis and a stage together, in the stage of "good situation", it is associated with getting acuity of distributive problems that created the virulence of the industrial process, without having to find a solution. Due to the increasing demands of partnership, the political system tries to create a complete conference between the masses and the elite ruling as far as possible. In the economic context, the government's effort is focused on improving the standard of living for different social strata. To satisfy these demands and pressures as well as to strengthen industrial structures, governments at this stage, put a broader distributive of power and wealth in their work programmed and in this regard, they seek a resolution for integration and distributive crises (Badie 77: 2008 ).

Distributive crisis can be considered from cultural and social aspects. Because the mechanism of distributive values among the various segments, has undergone the relation between the elite and the masses to a major transformation and it is considered as a determining factor. The main issue in this process is to create a compromise between large and small values. Because any interruption in this case, can aggravate other crises such as legitimacy and partnerships (Ghavam: 1995: 181).

\subsection{Ideology and the Distributive Crisis}

The word of ideology is created for the first time by Anthony Dastot Dotersi (1836-1754), who had hoped to conduct a systematic study for examining the idea roots of revolutions in the 1790s. Like many philosophers of the 18th century, Dotersi came close to the great English thinker Locke that the mind is a tabula rasa at birth, and a person is born without knowledge or idea. Therefore, everything we know and every idea we have, is the sensory experience product. Dotersi has used this introduction to explain his theoretical framework, meaning ideology or ideas science. Based on his opinion, ideas can be true or false and misleading. He sought to eliminate false ideas and replacing them with correct ideas.

Ideology acts as a kind of map for the selection procedure and political interpretation. In this respect, ideology guides, supports, limits, realizes the political action, and at the same time, it is used as the highest driving force of the political 
action of the masses. Leaders want to use ideology to justify their position or to give bad names to the views of others. In other words, ideology can be used either in the descriptive or motivational or in insulting meaning. Ideology, therefore, as usual, contains a philosophy that human nature, an economic program that offers the appropriate means of production and distributive and explains the political right structure to pursue through the program of economic and perfection of humanity (Alam, 2006: 85-84).

An ideology is important for the political elite under the terms of in the areas of distributive:

1) An ideology may be responsible for the production of demands that needs action (or inaction) on the part of the political role holder.

2) The ideologies may in line with changes that they are seeking to create them in society, affect the political elites' power widely.

3) Ideologies in place that the elites could mobilize the masses by them and justify their policies (sometimes also labeled "modernization" and included a fundamental break from tradition) become an indispensable tool (Lapalombara, 2001: 368).

Of the issues raised above, we can conclude that most ideologies appear on the one hand in times of crisis. Thus, ideology helps those who lack social benefits to reject the existing system or help those who lack social benefits to justify their privileges. And on the other hand, the system as a statement of fact has different fields and may be involved of laissez-faire Adam Smith's philosophy and "invisible hand" of the supply law and his demand as a social relations regulator to public control and the scientific socialism productive activity management.

On the economic aspect, the distributive crisis exacerbates caused by the inequitable distributive of wealth. While the vast majority of wealth and community resources placed at the disposal of a minority and the majority is deprived of subsistence, of course, this situation is worsening distributive crisis (Ghavam: 1995: 181).

\subsection{The Distributive Crisis and Natural Resources}

Lack of natural resources of a country severely and perhaps absolutely, limits the country's economic capabilities. In this case, there are two categories of ideas. Groups of theorists believe that the earth and other natural resources serve to limit economic growth; on the other hand, there are theories in which downward "law" of the earth will be removed consciously. In fact, the earth is not included as one of the critical variables in the model of economic growth. Theodor Shultz believes dogmatism and stagnation after the war (which is very widespread among the least developed countries) has been a frequent source of damage, according to the matter that the modern economic growth is very dependent on industrialization.

1) The most significant and obvious part, in developing countries, is the agricultural sector that in most cases, has the least power to help its and sometimes national interests. Where national policies emphasize on industrialization (probably doomed), it is exactly adopted and implemented to the detriment of that part of the economy, which according to Schultz, help the most important contribution to the economic growth. Industrial development and development after the Second World War, has created the gamut in terms of improving living conditions, life expectancy at birth, life expectancy and reduced mortality, that its result was more rapid population growth and their accommodation in the cities. The continuation of this process has turned the urbanization into one of the most important phenomena of our time, to the point where talk of the urban revolution in the world.

2) Another complex aspect of the fanatical insistence on industrialization is what can be called as "pseudo-urbanization". This pattern is where the real motivation is the movement of population from rural to urban areas that can absorb the masses of uneducated or illiterate peasants in order to achieve opportunities for the financial improvement.

It can be said that the expression of this mechanism at the country level is regional imbalances and at the regional and local level, giving priority to chosen areas, like big cities, that leads to the logical movement of migrant populations into centers of favorites (cities).

\subsection{Distributive Crisis and Human Resource}

Most of developing countries face with the severe shortage of law and order managers or have not a sufficient number of these managers, because training managers who are trained necessary education to meet the scientific-technical centralized planning, are at either very low, or are not existed. Newly established countries' elites affected by domestic demand, regarding more production or distributive, are generally feeling considerable pressure to change or modify the administrative structure.

Harbison and Myers state the issue of human resources in a quite brief manner "the organization of modern nations depends on people development and organization of human activity, or as Theodore Schultz also admits 
the distributive or redistributive problem solving requires unprecedented investment in people by countries that are still in the early stages of before or pre-industrialize (Lapalombara, 2001: 386). Elites in different countries, act in different ways for the distributive and redistributive policy. Economists, almost agree more or less on the answers to this question. For example, Akshtayn provides five types of government intervention for further growth

1) Providing a general capital of the community in the affairs such as rules, health, and education;

2) Appointing items from the overall economic capital such as central banks, roads and transport;

3) Developing a wide range of tools is designed to control economic behavior in both the area of investment and consumption area;

4) Performing direct economic initiatives;

5) Creation of centralized planning.

Myrdal said that the ideology of planning has an interconnection with a comprehensive commitment to the modernization in today's developing countries. Here the ideals of modernization include:

1) Rationality, identifying problems and their solutions;

2) Improving a wide range of human adverse conditions;

3) Increasing economic aspect technology;

4) Promoting what Myrdal called it "living levels";

5) A broader social and economic equality;

6) Strengthening attitudes and creating institutions that are better suited to make and accept change.

Implementation of these principles requires huge investments in education and training, or what Schultz and other (Lapalombara, 2001: 390-389), call human investments.

Human capital is a combination of knowledge and skills accumulated in the human resources system. Human capital requires investment on human resources of a collection to raise their efficiency, since these types of costs are done with the aim of the operation in the future, so it is called "investment in human resources".

The concept of investing in people involves a wide scope of investment, from the investment for period of formal schooling and training, to the specific cost of family care in pre-school age and health. Most economists believe that the lack of investment in human capital is the main cause of low economic growth and development of developing countries and until these countries do not improve education, the use of science and knowledge and increasing the level of professional skills, the productivity and efficiency of labor and capital remains at a low level and growth and development will happen slowly with heavier costs (www.persianblog.ir).

In the end, it must be said that the major difficulty in political scientist studies in connection with the distributive crisis is that they value the distributive economic size more than political and social aspects. Since the majority of third countries are "symbolic" and the distributive of values and symbols plays a decisive role in the process of development and political modernization, therefore, they cannot be considered like dealing with Western pluralistic societies, solely on economic aspects and distributive material.

\section{Conclusion}

In the development process, in particular political development, with any view to this process that can be seen, there is a transition lies in it, the transition from the existing situation to favorable situation. Almost, all societies undergo various crises in transition to development, that in the absence of empowerment in overcoming this crisis, communities will see numerous abnormalities. Crises are not in transition countries, but even in developed countries, too, must always prepare you to deal with a variety of crises and challenges. Societies to achieve political development, should pass behind quintuple crises (identity, legitimacy, participation, distributive and penetration), in case of inability to overcome these crises, these communities will see numerous abnormalities, penetration and distributed crises as the crises that have been less studied, are in connection with the five crises. This crisis can create many problems in case of lack of knowledge or proper management for a society that is moving to develop that with proper management have to deal with it. The penetration crisis manifests in the form of pressures on the elite, for the coherence of institutional and creating innovations. Today, the government intrusion into structures that previously were isolated from society, or were considered independent components, as well as governments expand their control to the remote parts of the national territory, while national orientation and political independence in countries had intensified mobilization of all resources. Modern citizen 
capacity is affected; resulting of such an effect is imposing the increasing demands on the modern citizen. At the same time, the result of efficient interaction of government with its physical and social environment develops the material facilities scope. Relation between capacity and penetration is an obvious relation and where, traditional resistance, diversity of identity, legitimacy insecurity, inequality or imbalance of distributive exist, by mobilizing resources and rationalization of them, the government domain measures will expand and the scope of the substantive of the government will expand.

A distributive crisis occurs within the framework of ideological issues, physical and human resources. "Revolution of rising expectations' (rapid increase of material demands of the people from the government and the responsibility of the government to the people's living standards) make up the main components of this crisis. Therefore, the reflection is the state of the present time in which cultural minor objectives and independent goals become political goals. Accordingly, the realization of the equality principle is all citizens should have an equal or similar level in different terms. Equal intensity reduces with the effect of stress on equality in opportunities and equality denial in the basic economic conditions. So to overcome the distributive crisis (in terms of physical, human, ideological resources), providing equal opportunities and facilities for all members of society, appropriate and proportionate distributive of facilities, technical- scientific needs should be done. In the context of the crisis, focusing instead of centralization in administrative and governmental structure, the use of local forces, institution building in order to create institutions of control and minor and local government, the creation of convergence rather than divergence and the supremacy of law in all societies should be applied.

\section{References}

Alem, A. R. (2006). Political science foundations. Tehran: Ney Publishing.

Badie, B. (2008). Political development (Translated by Ahmad Naqib Zadeh). Tehran: Ghumes publication.

Bashiriyeh, H. (2007). Wisdom in politics. Tehran, contemporary look.

Dayoob, S. C. (1998). the modernization and development: in search of alternative formats, translation Syed Ahmad Movaseghi. Tehran: Publication Ghomes.

Eyvazi, M. R. (2003). building strength and the second Pahlavi regime theories. Tehran, Islamic Revolution Documents Center.

Ghavam, A. (1992). Political development challenges. Tehran: Ghomes.

Ghavam, S. A. (1995). Theory of modernization and development review. Tehran: University of Shahid Beheshti.

Hatneh, B. (2009). Development Theory and the Three Worlds (translated by Ahmad Movaseghi). Tehran: Publication Ghomes.

Joseph, L. (2006). Crisis of governance capacity, political development crises and sequences, translation Gholamreza Khajeh sarvi. Tehran: Institute for Strategic Studies, 2001.

Kazemi, A. A. (1987). management of international crises. Tehran: Institute for Political and International Studies.

Kazemi, S. A. A. (1997). The crisis of modernity and political culture in contemporary Iran. Tehran: Publication Ghomes.

Pye, L. (1967). Aspects of Political Development. Boston: Little Brown.

Pye, L. et al. (2001). crises and sequences in the political. Tehran: Center for Strategic Studies.

Robinson, J. A. (1999). political - security Selected Articles crisis. Tehran: Center for Strategic Studies.

Sariol Ghalam Mahmoud. (1996). Development, Third World and the international system. Tehran, ambassador publication.

Seif Zadeh, H. (2009). fifteen models of modernization, development and political transformation. Tehran: Publication Ghomes.

Seif Zadeh, S. H. (1994). the different theories about the ways of modernization, development and political transformation. Tehran: Publication Ghomes.

Tajik, M. R. (2000). Crisis Management: A review of crisis measure analyzing methods in Iran. Tehran: a culture of dialogue.

\section{Copyrights}

Copyright for this article is retained by the author(s), with first publication rights granted to the journal.

This is an open-access article distributed under the terms and conditions of the Creative Commons Attribution license (http://creativecommons.org/licenses/by/3.0/). 